\title{
The effect of intensive care specialist on mortality in a Teaching Hospital in Turkey
}

\author{
İlkay Ceylan', Ebru Karakoç², İsa Kılıç ${ }^{3}$ \\ ${ }^{I}$ Intensive Care Department, University Of Health Sciences, Bursa Yuksek Ihtisas Training and Research Hospital, Bursa, Turkey \\ 'Intensive Care Department, Çankırı State Hospital, Çankırı, Turkey \\ Intensive Care Department, Bursa City Hospital, Bursa, Turkey
}

Received: 2020-12-08.

Accepted: 2021-03-26

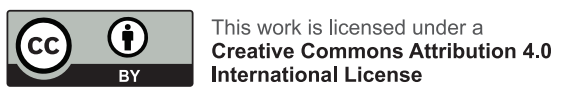

J Clin Med Kaz 2021; 18(3):14-17

Corresponding author:

Illkay Ceylan.

E-mail: ceylanilkay@yahoo.com;

ORCID: 0000-0003-3306-3107

\section{Abstract}

Aim: Specialization in critical care, which has a long history in various countries, is still developing in our country, and the practical outcomes of this relatively new discipline are yet to be not fully understood in our country. In the present study, we investigate the effect on mortality of the introduction of intensivists to a Level III closed intensive care unit.

Material and methods: The study was launched after being granted approval by the ethics committee. In this retrospective study we included the patients who were treated in the same period in two consecutive years. We excluded who were under the age of 18 years, who stayed in the intensive care unit for less than 24 hours and postoperative patients. For the purpose of the study, the patients were divided into intensivist and pre-intensivist groups.

Results: Aside from the shorter stay at the intensive care unit in intensivist group, mortality rate was lower in the pre-intensivist group, there was no statistically significant difference between the intensivist and pre-intensivist groups.

Conclusion: Intensivists have positive effects on patients' clinical outcomes, although a change in even a single factor during the treatment of ICU patients does not be sufficient for a statistical difference.

Key words: intensive care specialist, mortality, length of stay, intensive care

\section{Introduction}

An intensivist is a medical professional who has undergone training in critical patient care in a standardized program [1]. Such specialists are responsible for making clinical decisions and patient's admission to and discharge from Intensive Care Unit (ICU) [2]. Their interventions have been found to improve patient outcomes in the intensive care where a multidisciplinary approach is required $[3,4]$.

In Turkey ICUs are classified in three categories as 1st, 2nd and 3rd levels: Level 3 units are the services where a specialist doctor is available for 24 hours, laboratory and radiology services are provided and advanced invasive monitoring can applied. Level 3 ICUs are usually closed type ICUs which the responsible of the patient is an intensive care physician $[5,6]$. In our country usually anesthesiology and reanimation department's physicians are responsible for patients. Subspecialty training in intensive care medicine started in 2012, and first multidisciplinary intensivists started to take up positions in 2016. There is still a lack of data on the effect of intensivists on patients' outcomes in multidisciplinary ICUs in Turkey.

In this study we aim to investigate the effect of intensivists who started working in multidisciplinary ICUs on ICU patients' outcomes.

\section{Material and methods}

This study was launched after approval was granted by the Ethics Committee of the Republic of Turkey ........ ethical committee (dated ...... and No: ......). The study data was garnered from the records of patients admitted to a multidisciplinary adult ICU between January 1, 2017 and June 30, 2017, and between January 1, 2018 and June 30,2018 . The ICU in question provides services under the Anesthesiology and Reanimation Department of the TC SBÜ Bursa Yüksek İhtisas Training and Research Hospital, which is equipped with 17 Level III intensive care beds and four postoperative care beds.

Patients who stayed in the ICU for fewer than 24 hours, those who died within the first 24 hours of admission, and those who were admitted for postoperative 
care were excluded from the study. To ensure similar patient density and working patterns, and to reduce seasonal effects, the study included patients who stayed in the unit in the same period in two consecutive years.

The number of nurses was same in both periods for which the records were examined. The working pattern called for one nurse for every two patients, while dayshift physicians prior to 2018 worked in monthly rotations with two anesthesiology and reanimation specialists and one research assistant from the Anesthesiology and Reanimation Department. In August 2017, a physician with a subspecialty in intensive care started work in the general ICU of the hospital. Subsequently, in September 2017 the working pattern of intensive care physicians was given a permanent structure, with the intensivist as the team leader, supported by one anesthesiology and reanimation specialist and one research assistant from the Anesthesiology and Reanimation Department, working in monthly rotations. The night shift and holiday working schedule were same throughout the study, involving one research assistant with at least two years of experience, who was permanent member of staff in the ICU, and one on-call anesthesiologist who was responsible for ICUs and the operating room. The intensivist, when not in attendance available, was on-call via telephone in holidays and nights.

The patients were divided into an intensivist group, who were monitored and treated by the intensivist; and a preintensivist group, who were monitored by the anesthesiology and reanimation specialists. The hospital information management system and patient medical records were then accessed for data on causes of admission, referring departments, length of ICU stay, APACHE 2 score, age, gender and mortality rates.
All data were entered into and analyzed with the SPSS (Statistical Package for Social Sciences) for Windows 22 software package. For the data analysis, first, the assumptions that were to be met were tested for the determination of the required tests (parametric/non-parametric tests). The normality of distribution was analyzed with a Kolmogorov-Smirnov test, a Shapiro-Wilk test, kurtosis and skewness values, as the other assumptions of normal distribution, and histograms. An independent two-sample comparison was made with a t-test (Independent Samples t-test) for normally distributed data, while a Mann-Whitney U-test was applied to non-normally distributed data. The differences between two independent categorical variables were tested using Fisher's Exact Chi-square test when the assumptions were not met. The significance of the study results were interpreted based on a significance level of 0.05 .

\section{Results}

The number of patients who stayed in the ICU in the first six months of 2017 was 452, compared to 559 in the first 6 months of 2018. Of the total, 323 patients were excluded from the study for 2017 and 362 patients for 2018 due to admission for postoperative care and a stay of less than 24 hours. Consequently, the pre-intensivist group included 127 patients and the intensivist group included 197 patients. The characteristics of the study participants are presented in Table 1; both groups of patients had similar characteristics and APACHE 2 score.

The length of ICU stay was shorter in the intensivist group, although the difference was not statistically significant, and the length of stay at the ward after discharge from the ICU was shorter in the pre-intensivist group, with a statistically significant difference (Table 1).

\begin{tabular}{|c|c|c|c|c|}
\hline & & Pre-Intensivist & Intensivist & \multirow[t]{2}{*}{$P$} \\
\hline & & $(n=129)$ & $(n=197)$ & \\
\hline \multirow[t]{2}{*}{ Gender } & Female (n/\%) & $52 / 40.31$ & $79 / 40.10$ & \\
\hline & Male (n/\%) & $77 / 59.69$ & $118 / 59.90$ & \\
\hline \multicolumn{2}{|l|}{ Age (mean \pm SD) } & $61.53 \pm 21.42$ & $1.55 \pm 20.06$ & 0.993 \\
\hline \multicolumn{2}{|l|}{ APACHE 2 (mean \pm SD) } & $26.84 \pm 9.00$ & $25.80 \pm 7.28$ & 0.302 \\
\hline \multicolumn{2}{|l|}{ Length of ICU stay (days) (mean rank) } & 173.87 & 155.94 & 0.09 \\
\hline \multicolumn{2}{|l|}{ Mortality (n/\%) } & $47 / 33.07 \%$ & $84 / 42.63 \%$ & 0.26 \\
\hline \multicolumn{2}{|l|}{ Hospitalization after ICU (days) (mean rank) } & 101.28 & 204.25 & 0.01 \\
\hline \multirow[t]{11}{*}{ Diagnostic Categories of Patients (n/\%) } & Endocrinological & $1 / 0.78$ & $3 / 1.52$ & \\
\hline & Gastroenterological & $4 / 3.1$ & $10 / 5.08$ & \\
\hline & Intoxication & $3 / 2.33$ & $2 / 1.02$ & \\
\hline & Cardiac & $15 / 11.63$ & $14 / 7.11$ & \\
\hline & Malignancy & $2 / 1.55$ & $6 / 3.05$ & \\
\hline & Neurological & $35 / 27.13$ & $60 / 30.46$ & \\
\hline & Renal & $6 / 4.65$ & $3 / 1.52$ & \\
\hline & Sepsis & $6 / 4.65$ & $9 / 4.57$ & \\
\hline & Respiratory & $33 / 25.58$ & $58 / 29.44$ & \\
\hline & Trauma & $24 / 18.6$ & $31 / 15.74$ & \\
\hline & Hematological & $0 / 0$ & $1 / 0.51$ & \\
\hline \multirow[t]{4}{*}{ Department of referral (n/\%) } & Emergency Department & $77 / 59.99$ & $116 / 58.88$ & \\
\hline & External center & $12 / 9.3$ & $14 / 7.11$ & \\
\hline & Other ICU & $6 / 4.65$ & $13 / 6.6$ & \\
\hline & Wards & $34 / 26.36$ & $54 / 27.41$ & \\
\hline
\end{tabular}




\begin{tabular}{|l|l|l|l|}
\hline & $\begin{array}{l}\text { Pre-intensivist } \\
\mathrm{n}=129\end{array}$ & $\begin{array}{l}\text { Intensivist } \\
\mathrm{n}=197\end{array}$ & $\mathrm{P}$ \\
\hline Survived & $82 / 63,56 \%$ & $113 / 56,71 \%$ & 0.26 \\
\hline Died & $47 / 36.43 \%$ & $84 / 43,29 \%$ & \\
\hline
\end{tabular}

The pre-intensivist group of patients recorded lower ICU mortality than the intensivist group, but not to a statistically significant degree (Table 2).

\section{Discussion}

It is known that a full-time intensivist working in an intensive care unit (ICU) will have a positive effect on mortality [7,8]. In a study comparing 200 randomized surgical patients, one group of patients were under the care of a surgeon, while the other group was under the care of an on-site intensive care team. Although the patients under the intensive care team had higher disease severity (APACHE II) scores, their ICU stays were shorter, they were mechanically ventilated for a shorter time, there was less need for blood and blood products, and had around one-third of the complications as compared to the other group [9]. Morbidity and mortality have been show to decrease in several disease groups when hospital admission, follow-up, treatment and discharge decisions were made by an intensivist [10], although these studies were based on the open vs closed type of ICU working systems. In open unit model ICUs; patients are admitted under the care of an internist, family physician, surgeon, or any other primary attending physician, with the intensivists being available to provide their expertise via elective consultation [6]. These studies have generally demonstrated the positive effects of intensivists on mortality. In our country, ICUs have a relatively different working system, with critical patients cared for in closed intensive care units that are usually managed by the anesthesiology and reanimation departments. Anesthesiology is a medical discipline that takes an integrated approach to patients and diseases and has a wider perspective, unlike disciplines focused on specific organ systems. Accordingly, ICUs tend to be established under the anesthesiology and reanimation departments in our country, similar vein to the organizational structures seen in Europe [11]. Our study has compared the full-time intensivist period and the pre-intensivist period in the closed type ICU connected to the anesthesiology department, no statistically significant difference was identified in either mortality or length of ICU stay.

The intensivist started to work in the ICU in which the study was conducted in August 2017. The study periods were chosen specifically to avoid bias, and the same periods in two consecutive years were chosen to minimize the effects of other variables. No statistically significant difference in mortality was identified between the intensivist and the pre-intensivist groups for the two comparison periods, although a lower mortality rate was noted in the pre-intensivist group. Anesthesiologists were working in monthly rotations in ICU, and we believed that the reduced ICU adaptation of the physicians due to the working pattern of the pre-intensivist group may have had an impact on patient outcomes through the sense of provisionality towards the ICU. This orientation period of the new monthly working pre-intensivist may prolong the discharge and other therapeutic decision periods and end up with the long length of ICU stay in pre-intensivist group. Additionally, futile treatment may be avoided in the presence of a full-time intensivist in the ICU.
A previous study conducted in a cardiovascular surgical intensive care unit of a university hospital in our country compared the outcomes of postoperative patients managed by intensivists and by cardiovascular surgeons. It was found that outcomes such as mortality and length of ICU and hospital stay were similar in the postoperative period following cardiac surgery after intensivists started to manage cardiovascular ICU. While there was a shorter duration of mechanical ventilation, a lower requirement for blood and blood products, and decreased incidences of ICU readmission, all of which are significant indicators of morbidity [12].

Although not to a statistically significant degree, the length of ICU stay was clinically significantly shorter in the intensivist group in our study. The 1.5 times increase in the number of patients admitted in the same period suggests a quicker patient admission and discharge cycle, which may explain the increased patient admission. A protocol-based current approach, a sense of ownership of the ICU, patient-patient relative communication, and especially, continuity in communication with other intensive care staff may result as short length of ICU stay in intensivist group [13-15]. Additionally, the length of hospital stay in ward which evaluated among the patients discharged from the ICU to the ward, was longer and statistically significant in the intensivist group. Because of the approach of pre-intensivists although the patients were no longer indicated for ICU stay, they were expected to have complete or near-complete recovery in the ICU because these clinicians who could not adapt to the intensive care medicine [16]. The approach of intensivists, in contrast, is to discharge patients to the wards at a recovery level that is as yet unfamiliar to clinicians, which might have led to the longer wards stays.

Our study cannot be generalized to the whole country, because of different stuffing and working patterns in different kinds of hospitals. Majority of teaching hospitals ICU's managed by anesthesiology department but their stuffing patterns may be different. Also private hospitals, state hospitals and university hospitals have different working systems.

\section{Conclusion}

Our study is the first to investigate the effects of intensivists on patient outcomes in closed ICU in Turkey, but failed to demonstrate statistically the extent to which intensivist involvement improved mortality. No short-term effects on patient outcomes should be expected to result from a change in a single component of intensive care practice, which is carried out as a team. As such, long-term outcomes should be investigated in future studies.

Disclosures: There is no conflict of interest for all authors.

Acknowledgements: None.

Funding: None. 


\section{References}

1. Amin P, Robichaud AF, Divatia JV, Pelosi P, Altintas D, Eryüksel E, et al. The intensive care unit specialist: report from the Task Force of World Federation of Societies of Intensive and Critical Care Medicine. J Crit Care. 2016; 35:223-8. DOI: 10.1016/j.jcrc.2016.06.001

2. Valentin A, Ferdinande P, ESICM Working Group on Quality Improvement. Recommendations on basic requirements for intensive care units: structural and organizational aspects. Intensive Care Med. 2011; 37(10):1575-87. DOI: 10.1007/s00134-011-2300-7

3. Yang Q, Du JL, Shao F. Mortality rate and other clinical features observed in Open vs closed format intensive care units: A systematic review and meta-analysis. Medicine. 2019; 98(27):e16261. DOI: 10.1097/MD.0000000000016261

4. Klouwenberg PMK, Ong DYS, Bos LDJ, de Beer FM, van Hooijdonk RTM, Huson MA, et al. Interobserver agreement of Centers for Disease Control and Prevention criteria for classifying infections in critically ill patients. Crit Care Med. 2013; 41(10):2373-8. DOI: 10.1097/CCM.0b013e3182923712

5. TC Sağlık Bakanlığı Sağlık Hizmetleri Genel Müdürlüğü. 2008/53 Numaralı Yoğun Bakım Ünitelerinin Standartları Genelgesi. URL: https://www.saglik.gov.tr/TR,10979/yogun-bakim-unitelerinin-standartlari-genelgesi-200853.html. Last Access time 12 Jan 2021

6. Chowdhury D, Duggal AK. Intensive care unit models: Do you want them to be open or closed? A critical review. Neurology India. 2017; 65(1):39-45. DOI: 10.4103/0028-3886.198205

7. Nagendran M, Dimick JB, Gonzalez AA, Birkmeyer JD, Ghaferi AA. Mortality Among Older Adults Before Versus After Hospital Transition to Intensivist Staffing. Med Care. 2016; 54(1):67-73. DOI: 10.1097/MLR.0000000000000446

8. Costa DK, Wallace DJ, Kahn JM. The association between daytime intensivist physician staffing and mortality in the context of other ICU organizational practices: a multicenter cohort study. Crit Care Med. 2015; 43(11):2275. DOI: 10.1097/CCM.0000000000001259

9. Hanson CW, Deutschman CS, Anderson HL, Reilly PM, Behringer EC, Schwab CW, Price J. Effects of an organized critical care service on outcomes and resource utilization: a cohort study. Crit Care Med. 1999; 27(2):270-274. DOI: 10.1097/CCM.0000000000001259

10. Çelikel T. Dünyada ve Türkiye'de Yoğun Bakım Uzmanlığı. Yoğun Bakım Dergisi. 2001; 1(1):5-9.

11. Telci L. Gökten Üç Elma Düştü. J Turk Soc Intens Care 2020; 18(1):0-0

12. Topal ZB. Açık kalp ameliyatı geçiren hastalarda yoğun bakım uzmanı yöntemli hasta takibinin morbidite ve moralite üzerine etkisi. Ankara: Başkent Üniversitesi Tıp Fakültesi Anesteziyoloji ve Reanimasyon Anabilim Dalı Tıpta Uzmanlık Tezi. 2018.

13. Quenot JP, Ecarnot F, Meunier-Beillard N, Dargent A, Eraldi JP, Bougerol F, et al. What are the ethical dimensions in the profession of intensive care specialist? Annals of Translational Medicine. 2017; 5(4):47. DOI: 10.21037/atm.2017.09.34

14. Baykara N, Utku T, Alparslan V, Arslantaş MK, Ersoy N. Factors affecting the attitudes and opinions of ICU physicians regarding end-of-life decisions for their patients and themselves: A survey study from Turkey. PLOSONE. 2020; 15(5):e0232743. DOİ:10.1371/ journal.pone.0232743

15. Akpir K. Yoğun Bakım Etiği. J Turk Soc Intens Care. 2010; 8(2):77-84. DOI: 10.4274/tybdd.08.06

16. Gershengorn HB. Is My Intensivist Better Than Your Intensivist? Ann AM Thorac Soc. 2018; 15(3):312-314. 